\title{
LAPAROSCOPIC MINI GASTRIC BYPASS AS A REVISIONAL PROCEDURE AFTER FAILED PRIMARY RESTRICTIVE BARIATRIC SURGERY
}

\author{
Alaa Abbas Sabry, Hytham Mostafa Mohamed, Medhat Mohamed Helmy and \\ Mohamed Ahmed Fouad Elshimy*
}

Department General Surgery, Faculty of Medicine, Ain Shams University, Cairo, Egypt

\section{Corresponding:}

Mohamed Ahmed Fouad Elshimy

Mobile 01000388480

Email:

Drmohamed89elshimy@gmail.com

Received: 18/2/2020

Accepted: 10/3/2020

Online ISSN: 2735-3540

\begin{abstract}
:
Background: Restrictive bariatric procedures are commonly performed to induce weight reduction, however, some patients may require a second surgery due to inadequate weight loss, weight regain or late complications. Laparoscopic mini gastric bypass (LMGB) is a promising bariatric procedure, which provides an effective long-term weight loss and resolution of primary procedure related complications.
\end{abstract}

Aim of the Work: To assess laparoscopic Mini Gastric Bypass as a bariatric surgical technique for revision after failed primary restrictive bariatric procedure. Cause of revision, weight loss, resolution of primary procedure related co-morbidities and complication rates will be assessed.

Patients and Methods: This study included 60 patients with failed primary restrictive bariatric procedures (20 patients with failed sleeve gastrectomy, 20 patients with failed vertical banded gastroplasty and 20 patients with failed adjustable gastric banding) that were converted to laparoscopic MGB with minimal follow-up of 1 year.

Results: Among all patient samples (60 patients), there was significant decrease in mean body mass index after conversion to MGB. The mean BMI before revision was $42.80 \pm 3.43 \mathrm{~kg} / \mathrm{m} 2$ (range, $36-48.9$ ) that decreased to $32.51 \pm 3.31 \mathrm{~kg} / \mathrm{m} 2$ one year after revision. A significant improvement of obesity related co-morbidities was observed after one year, the incidence of remission of diabetes mellitus was $91.6 \%$, while it was $64.7 \%$ for hypertension and it was $70.5 \%$ for dyslipidemia. Reflux symptoms improved in about $80 \%$ of affected cases. Complications occurred only in 5\% of cases and they were successfully managed.

Conclusion: Mini gastric bypass is a safe and effective revisional procedure after failed primary restrictive bariatric surgery that adequate weight loss and satisfactory improvement of the primary procedure related complications.

Keywords: Bariatric surgery; Redo surgery; Revisional surgery; Mini/one anastomosis gastric bypass; Failed restrictive procedure.

\section{INTRODUCTION:}

Treatments for obesity include a range of therapies, such as dietary advice, physical activity, behaviour therapy, pharmacological therapy and bariatric surgery. The most pronounced weight loss is obtained by bariatric surgery. ${ }^{(1)}$

As the number of bariatric procedures performed increases, the number of patients requiring revisional procedures continues to 
rise , this comprises about $5 \%-15 \%$ of total cases of bariatric surgery ${ }^{(2)}$. The rate of revisional surgery is $10.5 \%-60 \%$ after LAGB (laparoscopic adjustable gastric banding) $)^{(3)}$ and about $38.5 \%$ at 10 years after SG (sleeve gastrectomy). ${ }^{(4)}$ The requirement for revisional surgery after VBG (vertical banded gstroplasty) is 29\%-39\% \% that may be needed within 10 years from the primary procedure $^{(5)}$.

Revision of primary bariatric surgery is mainly either due to inadequate weight loss or weight regain. other indications may be specific to the type of operation, in VBG, the cause of revision may be gastric outlet stenosis, staple line disruption, gastro gastric fistula, incisional hernia, band erosion and severe esophagitis $^{(6)}$. In AGB, revision may be due to hardware problems with the band itself, such as erosion and slippage, motility problems resulting in esophageal dilatation and psychological intolerance to the band ${ }^{(7)}$. In $\mathrm{SG}$, revision may be needed in case of gastro esophageal reflux due to trans-hiatal migration of the stomach, retained or dilated gastric fundus, a stricture or angulation of the stomach at the incisura causing severe dysphagia and solid food intolerance ${ }^{(8)}$.

Revisional options are variable, depending on primary procedure. MGB provides a safe and effective method for revision of failed primary restrictive bariatric procedure as it requires only a single anastomosis, thus provides a degree of technical simplicity, shorter learning curve, shorter operative time, the benefit of potentially fewer sites for anastomotic leaks to occur, decreasing potential sites for internal hernias to one Petersen's defect ${ }^{(9)}$.

MGB is an effective revisional option for sustained weight loss in morbid obese patients, in addition, it provides comorbidity resolution in more than $70 \%$ of patients. $^{(10)}$

With the advancement of laparoscopic surgical skills, several studies have recently demonstrated that laparoscopic revision can be performed safely by well-trained and highly experienced bariatric surgeons in specialized bariatric centers ${ }^{(11)}$. Although The complications of laparoscopic revision are reportedly $14.3 \%-46.3 \%$ compared with $3-27.8 \%$ of laparotomic one, advance of laparoscopic surgery has been due to the advantages it offers as it could provide a better vision with a close view and better dealing with deeply seated intra abdominal organs facilitating more precise dissection than laparotomic one. It is a minimally invasive technique thus causes less pain in the postoperative period, short hospital stay, early return to normal physical activity, better esthetic results and a decrease in incisional hernias. It also causes less alteration in systemic and immunologic stress $^{(12)}$.

\section{AIM OF THE WORK:}

The aim of current study is to assess laparoscopic Mini Gastric Bypass (LMGB) as a bariatric surgical technique for revision after failed primary restrictive bariatric procedure like Sleeve Gastrectomy (SG), Vertical Banded Gastroplasty (VBG) and Laparoscopic Adjustable Gastric Banding (LAGB). Cause of revision, weight loss, resolution of primary procedure related comorbidities and complication rates will be assessed.

\section{PATIENTS AND METHODS:}

Study Design: This is a prospective cohort study that has been conducted between December 2017 - December 2019 in Ain Shams University Hospitals, Cairo, Egypt.

Study Population: This study included 60 patients with failed primary restrictive bariatric procedures (20 patients with failed SG, 20 patients with failed VBG and 20 patients with failed LAGB) that were 
converted to LMGB with minimal follow-up of 1 year. All patients were operated with the same surgical team in Ain Shams University Hospitals.

Inclusion criteria: The patients included in this study fulfilled the following criteria:

- All patients were consented with the evaluation and treatment schedule.

- Patients fit for surgery.

- Adult male or female patient (age 18-60 years).

- Patients with BMI 35-50, presenting with failed primary restrictive bariatric procedure (weight loss of less than $50 \%$ of the excess body weight in 2 years, weight regain or having long term complications).

- Supportive family/ social environment

- No alcohol or substance abuse

Exclusion criteria:The patients who were excluded from the study:

- Patients unfit for operation.

- Patients younger than 18 years or older than 60 years.

- Patients with BMI less than 35 or more than 50

- Patients with multiple open abdominal procedures.

- Patients with any contraindications for laparoscopic surgery or anesthesia (e.g., having major medical co-morbidity such as cardiac patients).

- Patient with major psychiatric illness.

- Patient refusal.

Preoperative workup: All patients were subjected to the following:

- Full clinical history including past medical and surgical history.

- Preoperative co-morbid conditions such as hypertension and diabetes will be optimized whenever possible before surgery.
- Full clinical examination including BMI, anthropometric measures and vital signs.

- Nutritional assessment for vitamin B12, calcium, magnesium, iron and protein, fat, and carbohydrate body composition.

- Assessment of stomach pouch by dye study like gastro graffin meal.

- Routine preoperative investigations (like blood chemistries, ultrasonography, barium meal, and upper endoscopy).

- Lipid profile: cholesterol, triglycerides, LDL and HDL.

- Psychological assessment of the patient.

\section{Surgical Techniques:}

Antithrombotic precautions were taken for all patients by receiving LMWH (Clexane subcutaneous injection) 12 hours before operation together with intraoperative and postoperative crepe bandage for lower limbs. Also, appropriate preoperative antibiotic (one gram intravenous third generation cephalosporin) was administered with induction of anaesthesia.

After general anesthesia induction, the patient is positioned in reverse trendelenburg position with splitting of the legs (French position) and abducted arms. The patient was secured well to the operating table. After that, sterilization and draping of the area between nipple line and upper thigh was done. The surgeon stood between the patient's legs and the assistant to left of the patient, and the camera man to the right of the patient.

Pneumo-peritoneum was done through a Verress needle placed in left subcostal region at midclavicular line. A 10-12-mm trocar is placed under direct vision approximately $15 \mathrm{~cm}$ below the xiphoid and $2-3 \mathrm{~cm}$ to the left of midline. One $5 \mathrm{~mm}$ trocar is placed under xiphoid process for the insertion of the liver retractor, 12 and $15 \mathrm{~mm}$ trocars are placed on the right and left mid-clavicular lines few millimeters above the umbilicus, respectively. for the surgeon 
instruments, and another $5 \mathrm{~mm}$ trocar is placed on the left anterior axillary line for assistance. Oral Ryle is inserted to deflate the stomach to facilitate the dissection.

During conversion from LSG, lysis of typical adhesions after SG was done then a long gastric pouch was created by making a window to enter the lesser sac just proximal to the antrum. Through that window, a 60 mm green / blue Endo GIA stapler load (according to the stomach wall thickness) is passed horizontally below the crow's foot.. Insertion of 36 French bougie then 45 to 60 mm blue Endo GIA stapler loads are fired vertically to the axis of stomach creating a gastric tube, upward to the angle of His (under bougie tube guidance).

During conversion from LAGB, the first part of the procedure consisted of the band removal then creation of gastric pouch as before.

During conversion from VBG, we separate the stomach wall from the left lobe of the liver and overlying omentum in an attempt to identify the site of the mesh. Then, bougie with a size of 36 is inserted into the stomach, If it passed easily and freely without gastric outlet obstruction, the mesh is not removed and the first transverse staple line is placed at the level of the incisura and vertical stapling on the previous VBG staple line is then placed (in this case, the pouch is usually not dilated). If gastric outlet obstruction is found and did not allow the bougie to pass, the mesh is attempted to be removed without injuring the gastric wall. In case we succeeded and the bougie is passed easily, MGB is performed as described later. If we failed, the $1 \mathrm{st}$ transverse reload is to be taken just above the mesh and proceeded vertically to the angle of hiss.

MGB is done by identification of ligament of Treitz then a $200-\mathrm{cm}$ length of the small intestine was measured in $5-\mathrm{cm}$ increments and then brought up and sutured to the gastric stump. Ante-colic gastrojejunostomy is performed using $60 \mathrm{~mm}$ blue Endo GIA stapler load after a small incision was made with an ultrasound dissector at the anterior wall of the stomach and jejunum. The residual stoma is closed with vicryl $2 / 0$ continuous suture over a ryle tube inserted through the nasal cavity and carefully introduced through the stoma opening to efferent intestinal loop. The staple line and anastomosis are then tested for any leak through methylene blue test. The staple line is also evaluated for bleeding which can be controlled by endoclips. A tube drain is placed along the staple line and Trocar sites are closed with 0 Vicryl to prevent bowel herniation.

Postoperative care: Early postoperative follow up during hospital stay includes:

- Vital signs (blood pressure, pulse, temperature and respiratory rate)

- Blood sugar level

- Intra abdominal drain

- Abdominal examination

Ambulation and clear liquids will start on the night of the operative day.

Thrombosis prophylaxis (LMWH 40 Units once daily) on the first postoperative day until discharge. Routine gastrografin study will be done on the second postoperative day before discharge to exclude the leak. Proton pump inhibitor will be administrated for 4 months postoperatively.

Patients will be reviewed as outpatients clinic 10 days post operatively then at $1,3,6$ months and 1 year postoperative. Patients will be reviewed in outpatients clinic at any time if they develop any complaints in between previously scheduled follow up visits.

A low-caloric protein-rich liquid diet will be maintained over the first month and then other elements will be sequentially 
introduced under strict supervision and multi-vitamins will be systematically prescribed. Patients will be encouraged to initiate physical activity from the first postoperative week.

\section{Outcomes Assessment:}

- Weight loss: BMI and percentage of excess weight loss $(1,3,6$ and 12 months).

- General health condition: Improvement of primary procedure related complications (like vomiting, dysphagia or reflux).

- Any postoperative complications: in all scheduled and non-scheduled visits.

- Metabolic effect:

Calcium, vitamin D and vitamin B (6 and 12 months).

Lipid profile (Cholesterol, triglycerides, LDL and HDL) (6 and 12months).

Hypertension and diabetes mellitus (if present) (1, 3, 6 and 12 months.

Data collection: Standardized data collection was performed which included:

- Preoperative data:

- Age.

- Sex

- Primary operation

- Weight.

- Height.

- BMI before revision.

- Duration after primary operation.

- Co-morbidities before revision (DM, hypertension and dyslipidemia and sleep apnea).

- Surgical history.

- Cause of revision.

- Operative data:

- Operative time which was defined as the time from the first incision to the placement of the last suture.
- Intraoperative complications.

- Conversion to open procedure.

- One or two stage procedure.

- Postoperative care data:

- Intensive care unit admission.

- Postoperative pain.

- Hospital stay which was defined as the number of days in the hospital after surgery inclusive of the day of surgery.

- Follow up data:

- Early postoperative complications.

- Late postoperative complications.

- Follow up weight.

- Follow up of EBWL \%.

- Follow up BMI (1, 3, 6 and 12 months).

- Follow up of DM (FBS and Hb A1c) at (1, 3, 6 and 12 months)

- Follow up of Hypertension at (1, 3, 6 and 12 months).

- Follow up of Respiratory problems (sleep apnea).

- Follow up of Dyslipidemia (Cholesterol, triglycerides, LDL and HDL) (6 and 12 months).

- Primary procedure related complications after 1 year.

- Thrombo-embolic manifestations.

\section{Statistical Analysis:}

The data will be collected and statistically analyzed. Description of quantitative variable will be done as mean and standard deviation, and qualitative data as frequency.

Chisquare test will be used to compare the groups as regard qualitative variable.

Studentt test will be used to compare two groups as regard quantitative variable in parametric data.

ANOVA test will be used to compare categorical variables and means. 
The results will be considered as the following;

- $\quad$ Significant (S) with $\mathrm{P}<0.05$.

- Highly significant (HS) with $\mathrm{P}<0.01$.

- $\quad$ Non significant (NS) with $\mathrm{P} \geq 0.05$.

Analysis of data will be done using IBMSPSS software (statistical program for social science version 21 .

\section{RESULTS:}

This is a prospective cohort study that has been conducted between December 2018- December 2019 in Ain Shams
University Hospitals, Cairo, Egypt. It included 60 patients with failed primary restrictive bariatric procedure (20 patients with failed SG, 20 patients with failed VBG and 20 patients with failed LAGB) that was converted to laparoscopic MGB with minimal follow-up of 1 year.

\section{Preoperative personal and medical characteristics:}

As regard all sample patients, They were 35 females $(58.3 \%)$ and 25 males $(41.7 \%)$. The mean age was $40.07 \pm 10.1$ years. The mean BMI before revision was $42.80 \pm 3.43 \mathrm{~kg} / \mathrm{m} 2$. (table 1 )

Table (1) : Demographic data and characteristics of the studied patients.

\begin{tabular}{|l|c|c|}
\hline \multicolumn{2}{|c|}{} & No. $=\mathbf{6 0}$ \\
\hline \multirow{2}{*}{ Age } & Mean \pm SD & $40.07 \pm 10.10$ \\
\cline { 2 - 3 } & Range & $18-59$ \\
\hline \multirow{2}{*}{ Wex } & Female & $35(58.3 \%)$ \\
\cline { 2 - 3 } & Male & $25(41.7 \%)$ \\
\hline \multirow{2}{*}{ Height } & Mean \pm SD & $122.77 \pm 13.25$ \\
\cline { 2 - 3 } BMI before revision & Range & $96-169$ \\
\cline { 2 - 3 } & Mean \pm SD & $169.33 \pm 7.62$ \\
\cline { 2 - 3 } & Range & $150-187$ \\
\cline { 2 - 3 } & Mean \pm SD & $42.80 \pm 3.43$ \\
\hline
\end{tabular}

Co-morbidities among all patients before revision include: diabetes mellitus (20\%), hypertension (28.3\%), dyslipidemia (28.3\%) and sleep apnea (10\%). (table2)

Table (2) : Co-morbidities before revision among the studied patients

\begin{tabular}{|c|c|c|}
\hline Co-morbidities before revision & No. & $\%$ \\
\hline Medical Free & 29 & $48.3 \%$ \\
\hline HTN & 17 & $28.3 \%$ \\
\hline DM & 12 & $20.0 \%$ \\
\hline Dyslipidemia & 17 & $28.3 \%$ \\
\hline Sleep apnea & 6 & $10.0 \%$ \\
\hline
\end{tabular}

\section{Detailed data about performed procedures:}

The primary operation was laparoscopic sleeve gastrectomy (LSG) in 20 patients, vertical banded gastroplasty (VBG) in 20 patients that was performed laparoscopically (LVBG) in 15 patients and open (OVBG) in 5 patients and laparoscopic adjustable gastric banding (LAGB) in 20 patients. The mean duration for revision after LSG was $40.55 \pm 7.34$ months, while it was $55.40 \pm$
22.30 months after VBG and it was $30.35 \pm$ 4.33 months after LAGB.(table 3)

Cause of revision in LSG patients was inadequate weight loss in 11 patients $(55 \%)$, weight regain in 6 patients $(30 \%)$ and gastroesophageal reflux disease (GERD) that was intractable with medications and lifestyle changes in 3 patients $(15 \%)$. While in VBG, it was inadequate weight loss in 5 patients $(25 \%)$, weight regain in 9 patients $(45 \%)$ and intractable GERD in 6 patients 
(30\%). In LAGB the cause of revision was inadequate weight loss in 4 patients $(20 \%)$, weight regain in 6 patients $(30 \%)$, intractable GERD in 6 patients $(30 \%)$, band slippage in 2 patients $(10 \%)$ and food intolerance in 2 patients $(10 \%)$. (table 3$)$.

Table (3): Comparison between the three studied groups regarding duration after primary operation and cause of revision.

\begin{tabular}{|c|c|c|c|c|c|c|c|}
\hline & $\begin{array}{l}\text { Group A } \\
\text { (LSG) }\end{array}$ & Group B (VBG) & $\begin{array}{l}\text { Group C } \\
\text { (LAGB) }\end{array}$ & \multirow[t]{2}{*}{$\begin{array}{c}\text { Test } \\
\text { value }\end{array}$} & \multirow[t]{2}{*}{$\begin{array}{c}\text { P- } \\
\text { value }\end{array}$} & \multirow[t]{2}{*}{ Sig. } \\
\hline & & No. $=20$ & No. $=20$ & No. $=20$ & & & \\
\hline \multirow{2}{*}{$\begin{array}{c}\text { Duration after primary } \\
\text { operation (month) }\end{array}$} & Mean \pm SD & $40.55 \pm 7.34$ & $55.40 \pm 22.30$ & $30.35 \pm 4.33$ & \multirow[t]{2}{*}{$16.706^{\bullet}$} & \multirow[t]{2}{*}{0.000} & \multirow[t]{2}{*}{ HS } \\
\hline & Range & $28-57$ & $35-105$ & $25-39$ & & & \\
\hline \multirow[t]{5}{*}{ cause of revision } & Inadequate wt loss & $11(55.0 \%)$ & $5(25.0 \%)$ & $4(20.0 \%)$ & \multirow[t]{5}{*}{$14.357^{*}$} & \multirow[t]{5}{*}{0.073} & \multirow[t]{5}{*}{ NS } \\
\hline & Weight gain & $6(30.0 \%)$ & $9(45.0 \%)$ & $6(30.0 \%)$ & & & \\
\hline & Intractable GERD & $3(15.0 \%)$ & $6(30.0 \%)$ & $6(30.0 \%)$ & & & \\
\hline & Band slippage & $0(0.0 \%)$ & $0(0.0 \%)$ & $2(10.0 \%)$ & & & \\
\hline & Food intolerance & $0(0.0 \%)$ & $0(0.0 \%)$ & $2(10.0 \%)$ & & & \\
\hline
\end{tabular}

*:Chi-square test; $\bullet:$ One Way ANOVA test

In the LSG group, revisional mini gastric bypass (MGB) was done laparoscopic in all patients, while in VBG group, it was done laparoscopic in 18 patient and converted to open in only 2 patients due to severe adhesions between stomach, left lobe of the liver and overlying omentum. In this group, mesh was removed in 7 patients due to presence of gastric outlet obstruction. In LAGB group, MGB was done laparoscopic in 19 patients and converted to open only in 1 patient. In this group, removal of gastric band and conversion to MGB was done at one stage in 14 patients, while it was done as two stage procedure in 6 patients due intraoperative finding of gastric tube damage (table 4)

Table (4): Revisional procedures among the studied groups

\begin{tabular}{|c|c|c|}
\hline & No. & $\%$ \\
\hline Group A (LSG) & \multicolumn{3}{|c|}{} \\
\hline LMGB & 20 & $100.0 \%$ \\
\hline Group B (VBG) & 18 & $90.0 \%$ \\
\hline LMGB & 2 & $10.0 \%$ \\
\hline Open & 7 & $35.0 \%$ \\
\hline Mesh removed & 13 & $65.0 \%$ \\
\hline Mesh not removed & \multicolumn{3}{|}{} \\
\hline Group C (LAGB) & 19 & $95.0 \%$ \\
\hline LMGB & 1 & $5.0 \%$ \\
\hline Open & 14 & $70.0 \%$ \\
\hline 1 stage & 6 & $30.0 \%$ \\
\hline 2 stage
\end{tabular}

The mean operative time in LSG group was $98.60 \pm 10.95$ minutes, while it was $167.20 \pm 33.18$ minutes in VBG group (with average time 221.5 minutes after OVBG compared to 149.2 minutes after LVBG ). In LAGB group, the mean operative time was $94.60 \pm 6.79$ minutes. This reflects that there is highly statistically significant increase in operative time of revision after VBG especially OVBG - compared to that after LSG or LAGB. (table 5)

The mean hospital stay after revision in LSG group was $4.60 \pm 0.68$ days, while it was $6.40 \pm 2.46$ days in VBG group (with average time 10.4 days after OVBG compared to 5.06 days after LVBG ). The mean hospital stay after LAGB was $3.40 \pm$ 0.50 days. This reflects that there is highly statistically significant increase in hospital stay after revision of VBG - especially OVBG - compared to that after revision of LSG or LAGB (table 5). 
Table (5): Comparison between the three studied groups regarding operative time and hospital stay after revision

\begin{tabular}{|c|c|c|c|c|c|c|c|}
\hline & & $\begin{array}{c}\text { Group A } \\
\text { (LSG) }\end{array}$ & Group B (VBG) & $\begin{array}{l}\text { Group C } \\
\text { (LAGB) }\end{array}$ & \multirow[t]{2}{*}{$\begin{array}{c}\text { Test } \\
\text { value }\end{array}$} & \multirow[t]{2}{*}{$\begin{array}{c}\mathrm{P}- \\
\text { value }\end{array}$} & \multirow[t]{2}{*}{ Sig. } \\
\hline & & No. $=20$ & No. $=20$ & No. $=20$ & & & \\
\hline \multirow{2}{*}{$\begin{array}{l}\text { operation time } \\
\text { (minutes) }\end{array}$} & Mean \pm SD & $98.60 \pm 10.95$ & $167.20 \pm 33.18$ & $94.60 \pm 6.79$ & \multirow[t]{2}{*}{$78.883^{\bullet}$} & \multirow[t]{2}{*}{0.000} & \multirow[t]{2}{*}{ HS } \\
\hline & Range & $79-119$ & $136-231$ & $82-112$ & & & \\
\hline \multirow{2}{*}{$\begin{array}{c}\text { hospital stay } \\
\text { (days) }\end{array}$} & Mean \pm SD & $4.60 \pm 0.68$ & $6.40 \pm 2.46$ & $3.40 \pm 0.50$ & \multirow[t]{2}{*}{$20.243 \bullet$} & \multirow[t]{2}{*}{0.000} & \multirow[t]{2}{*}{$\mathrm{HS}$} \\
\hline & Range & $4-6$ & $4-11$ & $3-4$ & & & \\
\hline
\end{tabular}

\section{:: One Way ANOVA test}

As regard the post operative complications, in LSG group, only one patient developed post operative leakage that was treated with upper GI endoscopy and stent insertion, while in VBG group, two cases developed complications, one of them developed small bowel obstruction during recovery and laparotomy was needed 10 days after LMGB. Incarcerated herniation of small bowel to a trocar. wound was identified, reduction of herniated bowel and repair of the trocar wound was done. The other patient developed wound infection that improved by daily dressing. In LAGB group, all patients did well without noticed post operative complications.(table 6)

Table (6): Comparison between the three studied groups regarding post operative complications

\begin{tabular}{|c|c|c|c|c|c|c|c|}
\hline & & Group A (LSG) & $\begin{array}{c}\text { Group B } \\
\text { (VBG) }\end{array}$ & $\begin{array}{l}\text { Group C } \\
\text { (LAGB) }\end{array}$ & \multirow[t]{2}{*}{$\begin{array}{c}\text { Test } \\
\text { value }\end{array}$} & \multirow[t]{2}{*}{$\begin{array}{c}\text { P- } \\
\text { value }\end{array}$} & \multirow[t]{2}{*}{ Sig. } \\
\hline & & No. $=20$ & No. $=20$ & No. $=20$ & & & \\
\hline \multirow[t]{4}{*}{ Complications } & No & $19(95.0 \%)$ & $18(90.0 \%)$ & $20(100.0 \%)$ & \multirow[t]{4}{*}{$6.105^{*}$} & \multirow[t]{4}{*}{0.412} & \multirow[t]{4}{*}{ NS } \\
\hline & Leakage & $1(5.0 \%)$ & $0(0.0 \%)$ & $0(0.0 \%)$ & & & \\
\hline & $\begin{array}{l}\text { Small bowel } \\
\text { obstruction }\end{array}$ & $0(0.0 \%)$ & $1(5.0 \%)$ & $0(0.0 \%)$ & & & \\
\hline & Wound infection & $0(0.0 \%)$ & $1(5.0 \%)$ & $0(0.0 \%)$ & & & \\
\hline
\end{tabular}

\section{*:Chi-square test}

\section{Weight loss:}

Among all patient samples (60 patients) , there was highly significant decrease in mean body mass index after conversion to MGB. The mean BMI before revision was
$42.80 \pm 3.43 \mathrm{~kg} / \mathrm{m} 2$ that decreased to 32.51 $\pm 3.31 \mathrm{~kg} / \mathrm{m} 2$ one year after revision (range, 26.3 - 38.7). (table 7), (figure 1)

Table (7): BMI of all studied patients at different times of follow up

\begin{tabular}{|c|c|c|}
\hline \multicolumn{2}{|c|}{ BMI } & No. $=60$ \\
\hline \multirow{2}{*}{ Before revision } & Mean \pm SD & $42.80 \pm 3.43$ \\
\cline { 2 - 3 } & Range & $36-48.9$ \\
\hline \multirow{2}{*}{ After 1 m } & Mean \pm SD & $40.55 \pm 3.37$ \\
\cline { 2 - 3 } & Range & $34.5-46.5$ \\
\hline \multirow{2}{*}{ After 3 m } & Mean \pm SD & $37.86 \pm 3.43$ \\
\cline { 2 - 3 } & Range & $31.7-44.5$ \\
\hline \multirow{2}{*}{ After 6 m } & Mean \pm SD & $35.03 \pm 3.36$ \\
\cline { 2 - 3 } & Range & $28.8-41.4$ \\
\hline \multirow{2}{*}{ After 1 yr } & Mean \pm SD & $32.51 \pm 3.31$ \\
\cline { 2 - 3 } & Range & $26.3-38.7$ \\
\hline \multicolumn{2}{|c|}{ P-value } & $<0.001(\mathrm{HS})$ \\
\hline
\end{tabular}




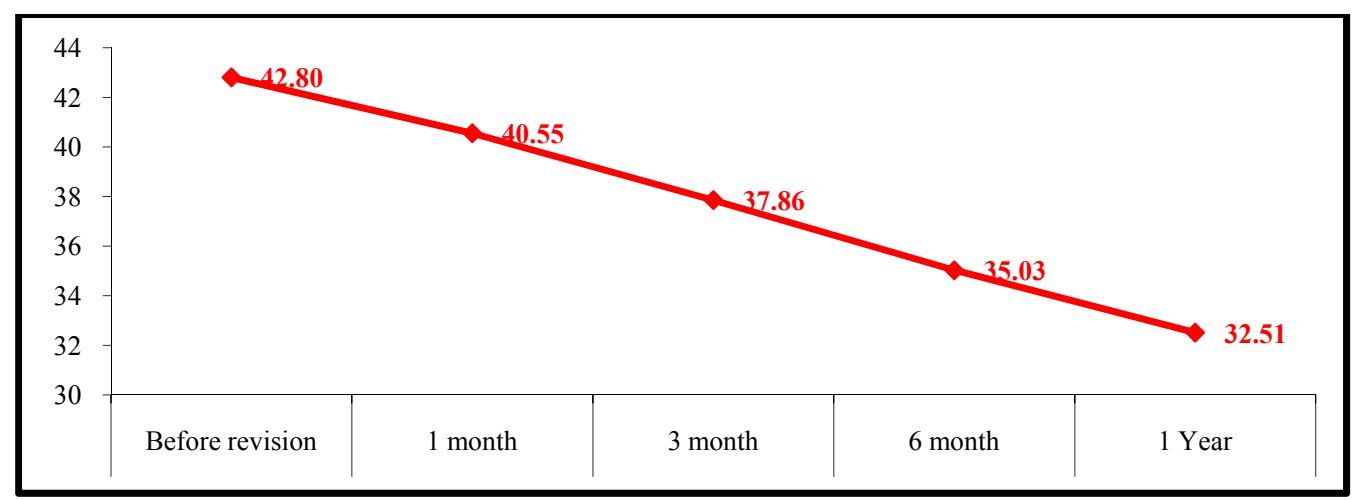

Figure (1) : BMI of all studied patients at different times of follow up

\section{$\underline{\text { Remission from co-morbidities }}$}

Among all studied patients, a significant improvement of obesity related comorbidities was observed one year after conversion to MGB. $64.7 \%$ of patients experienced remission from hypertension while $35.3 \%$ of them are still on antihypertensive drugs (but lower in dose or number). $91.6 \%$ of diabetic patients experienced remission from diabetes mellitus and only $8.4 \%$ still continues on lower dose of oral hypoglycemic drugs. About $70.58 \%$ of dyslipidemicbecame free and $66.6 \%$ of patients with sleep apnea became free. (table 8 )

Table (8): Co-morbidities among all studied patients before and after revision

\begin{tabular}{|c|c|c|c|c|c|c|}
\hline \multirow{2}{*}{ Co-morbidities } & \multicolumn{2}{|c|}{ Before revision } & \multicolumn{2}{c|}{1 year after revision } & \multicolumn{2}{c|}{ Disease remission } \\
\cline { 2 - 7 } & No. $=60$ & $\%$ & No. $=60$ & $\%$ & No. & $\%$ \\
\hline HTN & 17 & $28.3 \%$ & 6 & $10 \%$ & 11 & $64.7 \%$ \\
\hline DM & 12 & $20.0 \%$ & 1 & $1.6 \%$ & 11 & $91.6 \%$ \\
\hline Dyslipidemia & 17 & $28.3 \%$ & 5 & $8.3 \%$ & 12 & $70.58 \%$ \\
\hline Sleep apnea & 6 & $10.0 \%$ & 2 & $3.3 \%$ & 4 & $66.6 \%$ \\
\hline
\end{tabular}

Conversion to MGB improved primary procedure related complications especially intractable GERD. In LSG group, all symptomatic patients (3 patients) became symptom free 1 year after conversion, while in VBG group, 5 of 6 patients became symptom free after 1 year of conversion and only one patient still complaining of reflux symptoms. In LAGB group, 4 of 6 patients were cured after 1 year of conversion. (table 9).

Table (9): Follow up of GERD one year after conversion to MGB among the studied groups

\begin{tabular}{|c|c|c|c|c|c|c|c|c|c|}
\hline & \multicolumn{2}{|c|}{$\begin{array}{c}\text { Group A (LSG) } \\
\text { No. }=3\end{array}$} & \multicolumn{2}{c|}{$\begin{array}{c}\text { Group B (VBG) } \\
\text { No. }=6\end{array}$} & \multicolumn{2}{c|}{$\begin{array}{c}\text { Group C (LAGB) } \\
\text { No. }=6\end{array}$} & \multirow{2}{*}{ Test value } & P-value & Sig. \\
\cline { 2 - 9 } & No. & $\%$ & No. & $\%$ & No. & $\%$ & & & \\
\hline Improvement of GERD & 3 & $100.0 \%$ & 5 & $83.3 \%$ & 4 & $66.7 \%$ & 1.458 & 0.482 & NS \\
\hline Persistent GERD & 0 & $0.0 \%$ & 1 & $16.7 \%$ & 2 & $33.3 \%$ & & & \\
\hline
\end{tabular}

\section{DISCUSSION:}

Obesity is a serious, progressive disease with medical, social, psychological and economic Consequences ${ }^{(13)}$. It is considered a major risk factor for type 2 diabetes mellitus, hypertension, dyslipidemia, atherosclerosis, heart failure, cancer, liver disease, obstructive sleep apnea, infertility, 
degenerative joint disease, depression, and dementia $^{(14)}$.

Treatments for obesity include a range of therapies, such as dietary advice, physical activity, behaviour therapy, pharmacological therapy and bariatric surgery. The most pronounced weight loss is obtained by bariatric surgery as presented in a recent Cochrane review ${ }^{(1)}$.

Restrictive operations reduce the storage capacity of the stomach and as a result early satiety arises, leading to a decreased caloric intake. In general, they are simpler to perform and are accompanied by less procedural complications than malabsorptive procedures ${ }^{(15)}$.

While the majority of bariatric patients do achieve successful outcomes after their primary operation, the patients who present with insufficient weight loss, weight regain , continued co-morbid disease, acute or chronic complications after bariatric surgery may need reoperative procedure which are expectedly more complex with increased morbidity compared to primary bariatric procedures $^{(16)}$.

MGB represents an effective revisional option for sustained weight loss in morbid obese patients and it provides co-morbidity resolution in more than $70 \%$ of patients. ${ }^{(10)}$

Compared to RYGP, MGB it is considered a safe method for revision of failed primary restrictive bariatric procedure as it requires only a single anastomosis, thus provides a degree of technical simplicity, shorter learning curve, shorter operative time, the benefit of potentially fewer sites for anastomotic leaks to occur, decreasing potential sites for internal hernias to one Petersen's defect ${ }^{(9)}$.

Revisional procedures are complex and technically demanding. They are generally associated with a higher risk of postoperative complications than that of primary procedures, and the perioperative morbidity rate is about $19 \%-50 \%{ }^{(17)}$
MGB may be followed by several complications like nutritional deficiencies, marginal ulcer and stomal stenosis. One of the most serious complications is biliary gastro-oesophageal reflux which may cause oesophageal mucosal damage, Barrett's oesophagus and eventually gastric/ oesophageal cancer $^{(18)}$.

The current study has been conducted between December 2018- December 2019 in Ain Shams University Hospitals, Cairo, Egypt. It included 60 patients who were selected to meet our inclusion criteria and were operated -after a careful preoperative assessment - with the same surgical team with minimal follow-up of 1 year.

This study aimed to prospectively assess laparoscopic Mini Gastric Bypass as a suitable surgical technique for revision after failed primary restrictive bariatric procedure like Sleeve Gastrectomy, Vertical Banded Gastroplasty and Laparoscopic Adjustable Gastric Banding, as well as, to investigate Causes of revision, weight loss, resolution of primary procedure related co-morbidities and complication rates.

\section{Analysis of preoperative data:}

In the current study, the mean age of our participants was $40.07 \pm 10.10$ years and the mean BMI before revision was $42.80 \pm 3.43$ $\mathrm{kg} / \mathrm{m} 2$.

Co-morbidities among patients before revision included: diabetes mellitus $(20 \%)$, hypertension $(28.3 \%)$, dyslipidemia $(28.3 \%)$ and sleep apnea (10\%).

The primary operation was LSG in 20 patients, VBG in 20 patients that was performed laparoscopically (LVBG) in 15 patients and open (OVBG) in 5 patients and LAGB in 20 patients.

The mean duration for revision after LSG was $40.55 \pm 7.34$ months, while it was $55.40 \pm 22.30$ months after VBG and it was $30.35 \pm 4.33$ months after LAGB. 


\section{Causes of revision to MGB:}

Causes of revision in LSG group were inadequate weight loss in 11 patients $(55 \%)$, weight regain in 6 patients $(30 \%)$ and gastroesophageal reflux disease (GERD) that was intractable with medications and lifestyle changes in 3 patients (15\%).

Compared to the published results in the study of Sonja Chiappetta and his colleagues that compare between MGB and RYGB as a second step procedure after SG, causes of revision to MGB in 34 studied patients were inadequate weight loss in $64.7 \%$, weight regain in $20.5 \%$ and GERD in $14.7 \%$ of them ${ }^{(19)}$.

In VBG group, causes of revision were inadequate weight loss in 5 patients $(25 \%)$, weight regain in 9 patients $(45 \%)$ and intractable GERD in 6 patients (30\%).

Sarah Tevis et al. published their results of 34 patients for Revisional Surgery after Failed VBG and causes of revision were band related complications in $73.5 \%$ of patients and inadequate weight loss or weight regain in $26.5 \%$ of them. ${ }^{(20)}$

In AGB group, causes of revision were inadequate weight loss in 4 patients $(20 \%)$, weight regain in 6 patients $(30 \%)$, intractable GERD in 6 patients $(30 \%)$, band slippage in 2 patients $(10 \%)$ and food intolerance in 2 patients (10\%).

Compared to the published results, in the study of Luigi Piazza and his colleagues about revision of failed primary AGB to MGB in 48 consecutive patients, causes of revision was band related complications in $43 \%$ of patients, GERD in $31 \%$, inadequate weight loss in $15 \%$ and food intolerance in $11 \%$ of patients ${ }^{(21)}$.

\section{Analysis of operative data:}

Unlike the 5 years results published by Matthieu and his colleagues that were about 30 patients with failed restrictive procedures which have been converted to MGB where all procedures were laparoscopic without need to convert into open, ${ }^{(22)}$ in our study, revisional MGB was done laparoscopic in all patients except in 3 patients that were converted to open $(5 \%)$ ). 2 patient were in VBG group, where there were severe adhesions between stomach, left lobe of the liver and overlying omentum the remaining one was in AGB group.

In the current study, In VBG group mesh was removed in 7 patients due to presence of gastric outlet obstruction. In AGB group, MGB was done at one stage in 14 patients, while it was done as two stage procedure in 6 patients due intraoperative finding of gastric tube damage.

\section{Operative time:}

In our study, there was highly statistically significant increase in operative time of revision after VBG - especially OVBG - compared to that after LSG or LAGB. The mean operative time in LSG group was 98.6010 .95 minutes, while it was $94.60 \pm 6.79$ minutes in AGB group. In VBG group, it was $167.20 \pm 33.18$ minutes (with average time 221.5 minutes after OVBG compared to 149.2 minutes after LVBG ).

Compared to published results in the study of Mario Musella and his colleagues about Conversion from LAGB and LSG to MGB in 300 patients, the mean Operative time of revisional MGB was $94.4 \pm 3.1$ minutes after SG and it was $96.1 \pm 30.4 \mathrm{~min}$ after AGB. ${ }^{(23)}$

Salama and Sabry published their results of 60 patients that compare between laparoscopic RYGP and laparoscopic MGB as a Redo Surgery after Failed Open VBG. The mean Operative time of revisional MGB after VBG was $145.41 \pm 29.18$ minutes. ${ }^{(24)}$

\section{Analysis of postoperative data:}

\section{Hospital stay:}

In the current study, there was highly statistically significant increase in hospital stay after revision of VBG - especially 
OVBG - compared to that after revision of LSG or LAGB. The mean hospital stay after revision in LSG group was $4.60 \pm 0.68$ days, while it was $3.40 \pm 0.50$ days in AGB group. In VBG group, it was $6.40 \pm 2.46$ days (with average time 10.4 days after OVBG compared to 5.06 days after LVBG).

Compared to published results in the study of Sonja Chiappetta and his colleagues that compares between MGB and RYGB as a second step procedure after SG), The mean hospital stay after revision of SG to MGB was 5 days in all patients, following their intern protocol ${ }^{(19)}$.

Piazza and his colleagues published their results about revision of failed primary AGB to MGB in 48 consecutive patients where the mean hospital stay after revision was 3.25 days $^{(21)}$.

Salama and Sabry published their results of 60 patients that compare between laparoscopic RYGP and laparoscopic MGB as a Redo Surgery after Failed Open VBG. The mean hospital stay after conversion of VBG to MGB was $4.769 \pm 2.241$ days $^{(24)}$.

\section{Postoperative complications:}

Among all studied patients, complications occurred only in 3 patients (5\%). 2 cases of them were in VBG group. The first patient developed small bowel obstruction during recovery and laparotomy was needed 10 days after LMGB. Incarcerated herniation of small bowel to a trocar wound was identified, reduction of herniated bowel and repair of the trocar wound was done. The second one developed wound infection that improved by daily dressing. In SG group, only one patient developed post operative leakage that was treated with upper GI endoscopy and stent insertion.

Compared to 5 years results published by Matthieu and his colleagues that were about 30 patients with failed restrictive procedures which have been converted to MGB, 2 patients $(6.6 \%)$ experienced major early complications, one of them was perianastomotic abscess on postoperative day 14 and the other was port site incarceration of the small bowel on post operative day $4^{(22)}$.

\section{Body mass index:}

In the current study, there was statistically significant decrease in mean body mass index at 1, 3, 6 and 12 months after conversion to MGB. The mean BMI before revision was $42.80 \pm 3.43 \mathrm{~kg} / \mathrm{m} 2$ that decreased to $32.51 \pm 3.31 \mathrm{~kg} / \mathrm{m} 2$ after one year of follow up. This is considered reasonable when compared with the study done by Matthieu and his colleagues where the mean BMI before revision was $45.5 \pm 7$ $\mathrm{kg} / \mathrm{m} 2$ that decreased to $33 \pm 45 \mathrm{~kg} / \mathrm{m} 2$ after one year of follow up. ${ }^{(22)}$

\section{Co-morbidities resolution:}

Among all studied patients, a significant improvement of obesity related comorbidities was observed one year after conversion to MGB. $64.7 \%$ of patients experienced remission from hypertension while $35.3 \%$ of them are still on antihypertensive drugs (but lower in dose or number). $91.6 \%$ of diabetic patients experienced remission from diabetes mellitus and only $8.4 \%$ still continues on lower dose of oral hypoglycemic drugs. About $70.58 \%$ of dyslipidemic patients became free and $66.6 \%$ of patients with sleep apnea became free.

Compared to published results in the study of Sonja Chiappetta and his colleagues that compare between MGB and RYGB as a second step procedure after $\mathrm{SG}$, a significant improvement of obesity related comorbidities was observed one year after conversion to MGB. $66.7 \%$ of patients experienced remission from hypertension, $100 \%$ of affected patients experienced remission from type 2 diabetes mellitus, $61.5 \%$ of dyslipidemic patients became free and $80 \%$ of patients with sleep apnea became free ${ }^{(19)}$. 
In the current study, Conversion to MGB improved primary procedure related complications especially intractable GERD. Among all studied patients, $80 \%$ of affected patients (12 patients) became symptom free after 1 year of follow up. The remaining $20 \%$ (3 patients) were still having reflux symptoms. Upper gastro intestinal endoscopy and biopsy with histopathological examination were done to all of them which showed normal esophageal and gastric mucosa of the pouch.

the most serious controversy concerning the disadvantages of revision with MiniGastric Bypass was that Loop gastroenterostomy and short pouch can predispose to esophagitis and gastritis.

Kular et al., defined bile reflux after MGB as bilious vomiting and/or documented bile in the esophagus on upper GI endoscopy with presence of GERD-like symptoms.

Chevallier et al., evaluated bile reflux by endoscopic biopsies. The authors registered, as a sign of bile reflux, foveolar dysplasia only in $17.1 \%$ of patients at 2 years and $4.6 \%$ at 4 years. ${ }^{(18)}$

Bile reflux is not symptomatic in all patients and symptoms can be successfully treated pharmacologically in most cases. Some authors reported several patients requiring revisional surgeries for bile reflux. Noun and colleagues reported that $0.4 \%$ of their patients required conversion to RYGB for bile reflux while Bruzzi et al. reported a $1.6 \%$ conversion rate to RNYB for bile reflux. ${ }^{(26)}$

Musella et al., in a more recent publication reported that 12 of 28 patients who developed postoperative duodenogastro-esophageal reflux required surgical intervention, options included conversion to RYGB, and laparoscopic Braun enteroenterostomy. ${ }^{(9)}$

\section{Conclusion:}

Laparoscopic mini-gastric bypass is considered a safe operation for revision of failed primary restrictive bariatric procedure and shows reliable results for weight loss and co-morbidities resolution. However, it may be complicated some times by annoying complications like biliary reflux that needs a high index of suspicion and may require operative exploration.

\section{REFERENCES:}

1. Bennett, Mehta, Rhodes, et al., (2007): Surgery for morbid obesity. Postgrad Med J; 83: 8-15.

2. Bult, van Dalen, Muller, et al., (2008): Surgical treatment of obesity. Eur J Endocrinol; 158(2):135-45.

3. Chevallier, Arman, Guenzi, et al., (2015): One thousand single anastomosis (omega loop) gastric bypasses to treat morbid obesity in a 7-year period: outcomes show few complications and good efficacy. Obes Surg.; 25:951-958.

4. Colquitt, Picot, Loveman, et al., (2009): Surgery for obesity. Cochrane Database Syst Rev: CD003641.

5. Fournier, Gero, Jankechova, et al., (2016): Laparoscopic Roux en Y gastric bypass for failed gastric banding: Outcomes in 642patients. Surg Obes Relat Dis; 12 (2): 231-239.

6. Gorber, Tremblay, Moher, et al., (2007): A comparison of direct vs. self-report measures for assessing height, weight and body mass index: a systematic review. Obes Rev 8(4): 307-26.

7. Himpens, Dobbeleir, Peeter, et al., (2010): Long-term results of laparoscopic sleeve gastrectomy for obesity. Ann Surg ; 252: 319-24.

8. Kular, Manchanda, Rutledge, et al., (2014): A 6-year experience with 1,054 mini-gastric bypasses-first study from Indian subcontinent. Obes Surg.;24:1430-1435. doi: 10.1007/s11695-014-1220-3. 
9. Lin, Lee, Ser, et al., (2016): 15-year followup of vertical banded gastroplasty: comparison with other restrictive procedures. Surg Endosc 30: 489-494.

10. Luigi Piazza, Carla Di Stefano, Francesco Ferrara, et al., (2015): Revision of failed primary adjustable gastric banding to minigastric Bypass. Updates Surg. 67:433437.

11. Mario Musella, Vincenzo Bruni, Francesco Greco, et al., (2019): Conversion from laparoscopic adjustable gastric banding and laparoscopic sleeve gastrectomy to one anastomosis gastric bypass: preliminary data from a multicenter retrospective study. Surgery for Obesity and Related Diseases 15: 1332-1339.

12. Matthieu, Thibault, Franck, et al., (2016):Revisional single-anastomosis gastric bypass for a failed restrictive procedure: 5-year results. Surgery for Obesity and Related Diseases 12: 240-245.

13. Musella, Susa, Manno, et al., (2017): Complications following the mini/one anastomosis gastric bypass (MGB/OAGB): a multiinstitutional survey on 2678 patients with a mid-term (5 years) follow-up. Obes Surg.;27(11):2956-67.

14. Noel, Nedelcu, Eddbali, et al., (2017): "What are the long-term results 8 years after sleeve gastrectomy?," Surgery for Obesity and Related Diseases, vol.13, no. 7, pp. 1110-1115.

15. Robert, Poncet, Boulez, et al., (2011): Laparoscopic gastric bypass for failure of adjustable gastric banding: a review of 85 cases. ObesSurg 21:1513-1519.

16. Saarinen and Juuti (2017): Reply to "Key features of an ideal one anastomosis/mini gastric bypass pouch". Obes Surg.;27(6):1632.

17. Sarah Tevis, Michael, Garren, et al., (2011): Revisional Surgery for Failed
Vertical-Banded Gastroplasty. OBES SURG. 21:1220-1224.

18. Shimizu, Annaberdyev, Motamarry, et al., (2013): Revisional bariatric surgery for unsuccessful weight loss and complications. Obes Surg; 23:1766-73.

19. Sonja Chiappetta, Christine Stier, Oliver Scheffel, et al., (2018): Mini/One Anastomosis Gastric Bypass Versus Rouxen-Y Gastric Bypass as a Second Step Procedure After Sleeve Gastrectomy. Obesity Surgery, https://doi.org/10.1007/ s11695-018-03629-y.

20. Spyropoulos, Argentou, Petsas, et al., (2012): Management of gastrointestinal leaks after surgery for clinically severe obesity . SurgObesRelat Dis ;8:609-15.

21. Salama Tand Sabry K (2016): Redo Surgery after Failed Open VBG: Laparoscopic Minigastric Bypass versus Laparoscopic Roux en Y Gastric BypassWhich Is Better?. Minimally Invasive Surgery. Article ID 8737519, 4 pages.

22. Van Dessel, Hubens, Ruppert et al., (2008): Roux-en-Y gastric bypass as a re-do procedure for failed restricive gastric surgery. SurgEndosc. ;22:1014-1018.

23. van Wezenbeek, Smulders, de Zoete, et al., (2015): Long-term results of primary vertical banded gastroplasty. ObesSurg ;25(8):1425-1430.

24. Victorzon (2012): Revisional bariatric surgery by conversion to gastric bypass or sleeve: good short-term outcomes at higher risks. Obes Surg. ;22:29-33.

25. Whitmer, Gustafson, Barrett-Connor, et al., (2008):Central obesity and increased risk of dementia more than three decades later. Neurology 71: 1057-1064.

26. Zhang, Chang, Eagon, et al., (2015): Perioperative risk and complications of revisional bariatric surgery compared to primary Roux-en-Y gastric bypass. Surg. Endose; 29(6):1316-20. 
التحويل المصغر لمسار المعدة للامعاء بالمنظار بعد فثل العمليات القائمة على تصغير المعدة لمرضى المقل السمنة المفرطة

علاء عباس صبري، هيثم مصطفي محمد، ملحت محمد حلمي،محمد احمد فؤاد الثيمي

الخلفية: يرجع فثل عمليات السمنة القائمة علي تصغير حجم المعدة الي عدم نقص كاف فى الوزن او زيادة فى الوزن مرة اخرى بعد العملية او وجود مضاعفات بعد اجعات الجراء العملية.

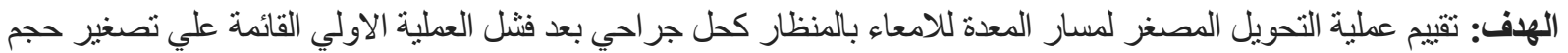

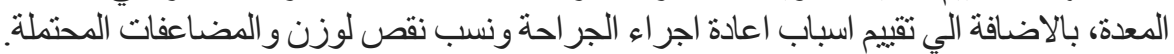

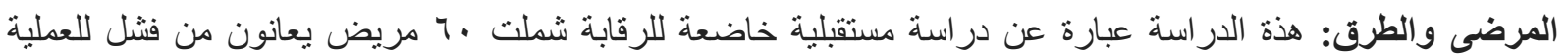

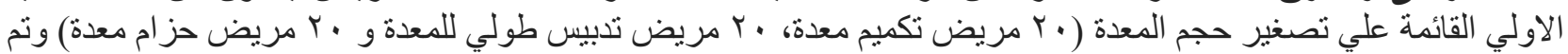

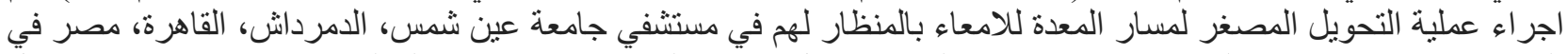

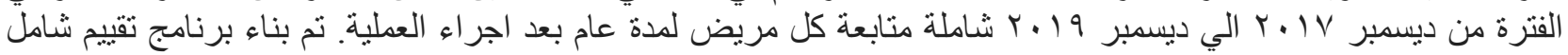

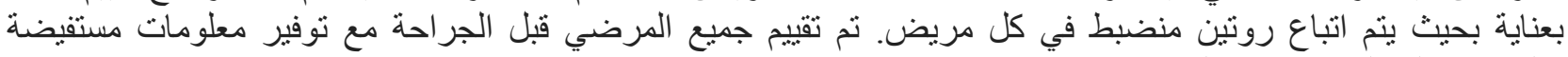
و المو افقة علي المشاركة في الدر اسة.

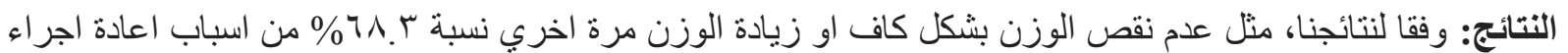

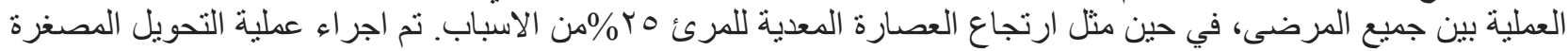

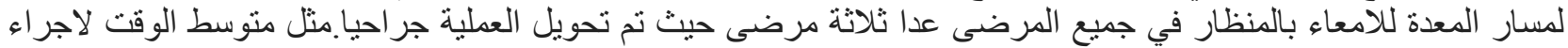

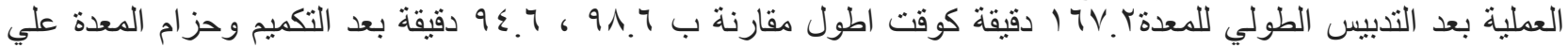

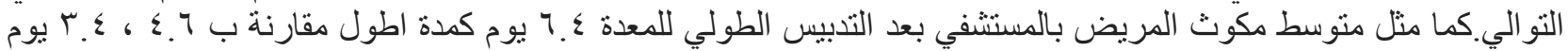

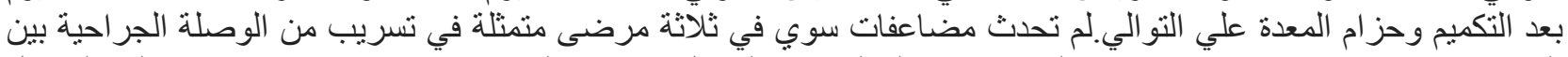

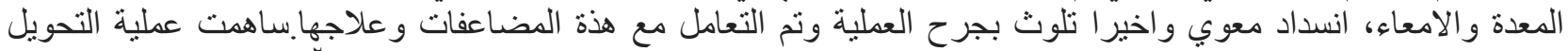

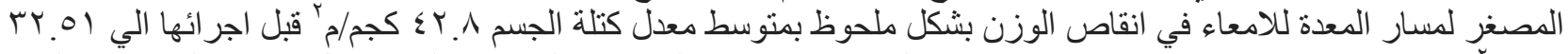

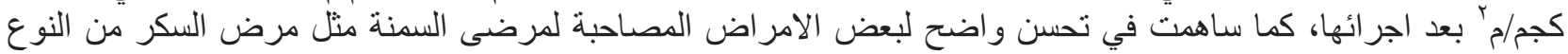

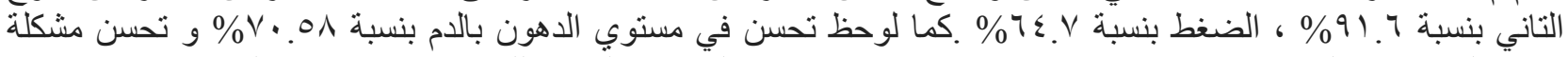

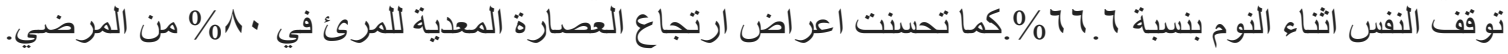

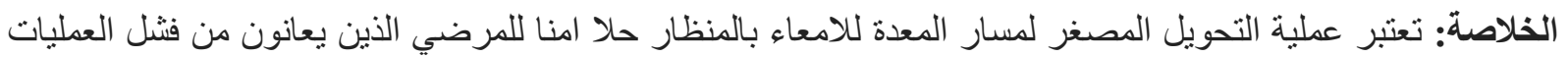

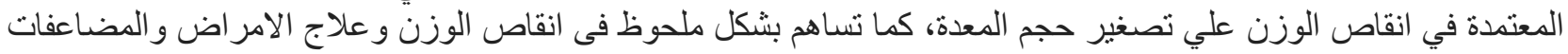

